\title{
Delayed Alumina Scale Spallation on Rene'N5+Y: Moisture Effects and Acoustic Emission
}

\author{
James L. Smialek and Gregory N. Morscher \\ NASA Glenn Research Center \\ Cleveland, $\mathrm{OH} 44135$
}

\begin{abstract}
The single crystal superalloy Rene'N5 (with or without Y-doping and hydrogen annealing) was cyclically oxidized at $1150^{\circ} \mathrm{C}$ for 1000 hours. After considerable scale growth ( $\geq 500 \mathrm{hr}$.), even the adherent alumina scales formed on Y-doped samples exhibited delayed interfacial spallation during subsequent water immersion tests, performed up to 1 year after oxidation. Spallation was characterized by weight loss, the amount of spalled area, and acoustic emission response. Hydrogen annealing (prior to oxidation) reduced spallation both before and after immersion, but without measurably reducing the bulk sulfur content of the Y-doped alloys. The duration and frequency of sequential, co-located acoustic emission events implied an interfacial crack growth rate at least $10^{-3} \mathrm{~m} / \mathrm{s}$, but possibly higher than $10^{2}$ $\mathrm{m} / \mathrm{s}$. This is much greater than classic moisture-assisted slow crack growth rates in bulk alumina $\left(10^{-6}\right.$ to $10^{-3} \mathrm{~m} / \mathrm{s}$ ), which may still have occurred undetected by acoustic emission. An alternative failure sequence is proposed: an incubation process for preferential moisture ingress leads to a local decrease in interfacial toughness, thus allowing fast fracture driven by stored strain energy.
\end{abstract}

\section{INTRODUCTION}

Alumina scale formation and spallation is a primary consideration for Ni-base alloys used in high temperature, oxidation resistant applications. Slow scale growth rates and thin scales are common 
attributes of alumna scales, however the adhesion of alumina scales can be variable. Historically, reactive element dopants, such as $\mathrm{Y}, \mathrm{Hf}, \mathrm{Zr}$, etc., have been added in small quantities to produce adhesion. In the case of single crystal superalloys, $\mathrm{Y}$ (and possibly La) have been found to be much more effective than $\mathrm{Hf}, \mathrm{Zr}$, or Ti. More recently, adhesion has been produced on dopant-free alloys by reducing the sulfur impurity content to below $0.5 \mathrm{ppmw}$. This was originally demonstrated by hydrogen annealing [1], but is now commercially produced by melt desulfurization. Both Y-doping and desulfurization require extra processing efforts and cost penalties. In the present study, the relative benefits of Y-doping and desulfurization on cyclic oxidation resistance were evaluated in order to determine critical Y/S ratios needed for adhesion. Some success in this area identified a 1:1 atomic ratio as an approximate figure of merit, at least when sulfur was present at or below about 10 ppma (6 ppmw) [2].

In the course of this and similar studies, it was found that scale spallation may occur hours or days after the initial cool-down and that moisture or water immersion promotes additional spallation [ 3-7]. A recent comprehensive study of the effects of water vapor on the oxidation of PWA 1480, PWA 1484, CMSX-4, aluminide coatings, and CoCrAlY showed that moisture had little effect on scale growth rate, but dramatically increased the rate of spallation in cyclic tests [7]. In general, alloys which did not form strongly adherent scales were adversely affected by moisture, whereas low sulfur (adherent) alloys were not affected, even when the adherent scales were intentionally damaged. For this reason, a specified procedure of water immersion was performed in the present study after 500 and 1000 hours of testing for Rene N5 \pm Y alloys. The amount of additional spallation was monitored by weight measurement, surface appearance, and, in select cases, acoustic emission. It was observed during the course of this study that even Y-doped alloys exhibited spallation during immersion after a considerable amount of strain energy had been built up by oxidation for $500 \mathrm{hr}$. Immersion-induced spallation was accompanied by audible 'pings' or high frequency reports, which began after a relatively short immersion time and continued noticeably for an hour or more. Therefore acoustic emission was incorporated into the test sequence toward the end of the program for a set of four Y-doped alloys which had not yet been immersed.

Acoustic emission (AE) has been traditionally used to monitor alumina scale cracking during high temperature exposure and during cool down. Since oxidation temperatures are too high for the 
actual AE sensors, waveguides were attached to the coated metal either in the form of rods [8-10] or wires $[11,12]$. In these studies a small amount of AE activity occurred at high temperature, but a more significant amount occurred on cooling. In fact, for the most part, the rate of AE activity increased as the sample temperature was cooled. This is consistent with the accepted view that the majority of scale spallation results from thermal expansion mismatch stress, which increases commensurately as the cooling temperature is decreased. While very informative in defining spallation events during cooling, $\mathrm{AE}$ has not been widely used to record spallation events after cool-down or during water immersion. The purpose of this paper is to present some initial results of moisture-induced alumina AE spallation

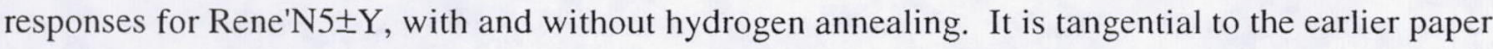
focussed on critical Y/S ratios required for scale adherence on Rene'N5 and the effects of hydrogen annealing and water immersion on scale adhesion [2].

\section{EXPERIMENTAL}

Coupons of René N5 $(0.3 \times 1.3 \times 2.5 \mathrm{~cm})$ were obtained from General Electric Aircraft Engines having 10 different yttrium levels, ranging from 0 to 100 ppmw. The Y-free alloy contained 2.6 ppmw sulfur and the 9 doped samples contained 3.6-6.5 ppmw sulfur. The details of sample characterization and experimental procedure have been presented in the previous report [2 LesEmbiez]. Hydrogen annealing $\left(5 \% \mathrm{H}_{2} / \mathrm{Ar}\right.$ at $1250^{\circ} \mathrm{C}$ for $\left.100 \mathrm{~h}\right)$ duplicate samples reduced the sulfur content of the undoped alloy to below the 0.01 ppmw detection limit of glow discharge mass spectroscopy (GDMS). However the sulfur content of the Y-doped alloys was not reduced. Carbon was the only other element reduced during annealing (typically from 400-600 ppmw initially, down to 100-150 ppmw after annealing); 45 other impurity elements, ( $\mathrm{P}, \mathrm{Na}, \mathrm{Ca}, \mathrm{In}, \mathrm{Pb}$, etc.), were not reduced substantially.

The coupons were cyclically oxidized (1-h heating to $1150^{\circ} \mathrm{C}$ and $10 \mathrm{~min}$. cooling to $100^{\circ} \mathrm{C}$ ) for 1000 1-h cycles. Weights, visual observations, and behavior in water immersion tests were recorded after cool-down at various intervals, primarily at 500 and $1000 \mathrm{~h}$. The relative amount of spalling to bare 
metal was determined from image analyses of $10 \mathrm{x}$ macrographs, using the commercial program, PAX-it-. Acoustic emission was performed on alloys 53, 88, 103, and 105 (nominal ppmw Y) during 24 hr water immersion exposure after cool-down from the $1000^{\text {th }}$ test cycle. In order to monitor coating cracking, two AE sensors were clamped to the specimen prior to water immersion. Vacuum grease was used as a couplant between the sensor and the coupon. The sensors used were only $6.35 \mathrm{~mm}$ in diameter ${ }^{\#}$ and were sensitive to frequencies ranging from $\sim 100$ to $700 \mathrm{kHz}$. Acoustic emission waveforms were digitially recorded using a 2-channel, Fracture Wave Detector (FWD) ${ }^{*}$. The FWD consisted of a Pentium 233 $\mathrm{MHz}$ based computer with a 12-bit, $30 \mathrm{MHz}$ acquisition A/D board. Each sensor was connected to a preamplifier and filter trigger module that was fed into the computer. The preamplifier was set at $20 \mathrm{~dB}$, the filter signal was amplified $18 \mathrm{~dB}$ and the filter trigger was amplified $21 \mathrm{~dB}$. The capture rate was set so that the time length saved for each digitized waveform was 102.4 microseconds, including a 20.4 microsecond pretrigger before the waveform, to clearly delineate the beginning of the waveform.

The post-test analysis was performed using Wave Explorer ${ }^{\mathrm{TM}}$ software provided by the FWD manufacturer. First, some events (usually less than $5 \%$ of the total) were removed from the data set. They were deemed as not pertinent to scale spalling according to three criteria:

(1) events that occurred during insertion of the specimen into the water due to rubbing of the coupon against the sides of the beaker - low frequency events.

(2) electro-magnetic interference - high frequency events of short duration, having the same time of arrival on both sensors.

(3) events that were the continuation of the previous event - no clear beginning to the waveform.

The sorted data was then analyzed according to the number of events and cumulative AE energy (summation of the individual waveform energies) over the time of the immersion experiments.

\footnotetext{
- Midwest Information Systems, Franklin Park, IL.

" Pico sensors, Physical Acoustics Corp., Princeton, NJ.

* Digital Wave Corporation, Englewood CO.
} 


\section{RESULTS}

Weight change. The primary oxidation results were discussed in the previous report [2]. The asreceived, undoped alloy exhibited considerable spallation and a final weight loss of more than $40 \mathrm{mg} / \mathrm{cm}^{2}$. The as-received, Y-doped samples lost 0.7 to $1.4 \mathrm{mg} / \mathrm{cm}^{2}$, showing no trend with Y level. All the hydrogen-annealed samples produced a small weight gain of 0.6 to $1.0 \mathrm{mg} / \mathrm{cm}^{2}$, again showing no trend with Y-level.

After $500 \mathrm{hr}$ of exposure all the samples were immersed in water for 1-4 hr. The additional spalling due to immersion alone is shown in Fig. 1. Here it can be seen that the as-received samples lost measurable amounts of scale, up to $1.5 \mathrm{mg} / \mathrm{cm}^{2}$, with no apparent correlation with Y content. That is to say, even Y-doping did not preclude moisture-induced spallation. In constrast, except for the undoped sample, the hydrogen-annealed samples exhibited minimal $\left(<0.05 \mathrm{mg} / \mathrm{cm}^{2}\right)$ additional spallation.

After $1000 \mathrm{hr}$ oxidation, the situation is more complicated, as summarized in Fig. 2. First, only alloys $0-53 \mathrm{Y}$ were immersed directly (within hours) after the oxidation test was completed. The other alloys (67-105 Y) remained at ambient conditions for 1 year before immersion, and the as-received samples of these did not exhibit as much massive immersion-induced spallation as at $500 \mathrm{hr}$. They appear to have been stabilized. Secondly, the hydrogen-annealed samples of these four alloys anomalously exhibited weight loss similar to the as-received samples, but did not visually exhibit much area of spalling to bare metal. This may have resulted from the ultrasonic cleaning performed to remove the AE coupling grease by dislodging loose scales in the few areas of accelerated attack (pits and corners). Third, (and conversely), the hydrogen-annealed samples from alloys $16-48 \mathrm{Y}$, immersed soon after oxidation, did visually exhibit considerable, albeit very localized, moisture-induced spallation as compared to immersion after $500 \mathrm{hr}$. Fourth, the as-received, undoped ( $0 \mathrm{Y})$ sample exhibited excessive weight loss due to accelerated attack at the specimen edges and loss of non-protective $\mathrm{Ni}, \mathrm{Cr}$-oxides. And, finally, the hydrogen-annealed, undoped sample exhibited much less moisture-induced spallation at $1000 \mathrm{hr}$ than at $500 \mathrm{hr}$. 
The $1000 \mathrm{hr}$ weight change data and the effect of immersion is summarized in Table I for each of the alloys (nominal Y-level), oxidized in both the as-received and $\mathrm{H}_{2}$-annealed conditions. Since many of the results show a general equivalence regarding specific Y-level, the response for all the doped alloys is also shown as an overall average.

Acoustic emission. The AE data was obtained only for Y-doped alloys 53, 88, 103 and 105 after $1000 \mathrm{hr}$ of oxidation at $1150^{\circ} \mathrm{C}$. The number of $\mathrm{AE}$ events and cumulative energy are shown in Figures 3-6 and Table II for the four coupon-pairs monitored. The first pair (53 Y samples) was immersed in water within one day of oxidation, whereas the remaining pairs were immersed in water approximately one year later. The event labels on Figures 5 and 6 illustrate the time interval for a series of closely associated, consecutive individual spalling events. On average, the elapsed time interval corresponding to one event is most often a fraction of a second. Table II shows the total number of AE events and cumulative energy for each specimen tested. Three observations are clear from the all the AE data. First, the rate of AE activity decreased with immersion time. Second, for all the pairs of coupons evaluated, roughly an order of magnitude greater amount of AE activity occurred for the alloys without hydrogen annealing compared to the same alloys that had been annealed. Third, more AE activity occurred for the specimens immersed shortly after oxidation compared to those tested one year later. Some of the latter effect is real, but some is probably artifact caused by a higher clamping pressure of the sensors for the 53 Y (immediately immersed) samples.

The weight losses for the samples of alloy $53 \mathrm{Y}$, immersed shortly after oxidation, are consistent with the AE results in showing more moisture-induced spallation for the as-received condition compared to hydrogen annealing. Unfortunately, no direct correlation between AE response and weight loss could be discerned for alloys 88-105 Y. These had been cleaned ultrasonically after the AE measurements, which apparently affected the weight loss even though the visual differentiation in spalled area was as expected.

One interesting observation that pertained to all the specimens was that a number of associated events often occurred within a fraction of a second to a few seconds, and each individual event had a duration on the order of 300 microseconds. Examples of waveform signals from two AE events, less than 
about 200 milliseconds apart, are shown in Figure 7. One waveform example (A1) shows the response at sensor 1. Another waveform recorded 200 milliseconds after the end of the previous event (B1) exhibits a similar pattern, although it is a temporally separate event. The related set of waveforms, (A2 and B2), recorded by sensor 2 , also had nearly identical waveforms occurring over the same time interval as those at sensor 1 .

These characteristics can be understood from the general response of sound waves in a solid medium. An acoustic waveform of a thin plate (thickness much less than the acoustic wavelength) is a superposition of the initial extensional and flexural waves, plus reflections of these waves from the sample edges $[13,14]$. Only the first few peaks of the waveform in figure 7 are the "pure" extensional and flexural waveform components of the fracture event, most are reflections. The first peak is known to be extensional, because it is the fastest wave. It can be used for accurate location analysis when multiple sensors are used [14].

The shape and time of arrival of an AE waveform is controlled by the source event, the distance traveled to the sensor, and the elastic properties and geometry of the medium [15]. The difference in the time of arrival at each sensor was the same short interval $(<1$ s) for two sequential events 'A' and 'B'. Also the shape and frequency content of the two successive events was similar at the same sensor, cf. A1 with $\mathrm{B} 1$ and $\mathrm{A} 2$ with $\mathrm{B} 2$. It is therefore reasonable to conclude that events $\mathrm{A}$ and $\mathrm{B}$ originated from the same location and indicate the same kind of fracture source event. They are therefore sequential and correlated as to location and type of fracture. The same reasoning holds for three successive events (C, $\mathrm{D}$, and $\mathrm{E}$ ) that occurred at a different time and location, as shown in figure $7 \mathrm{~b}$. Rapid and repetitive acoustic emission events from exactly the same sample location, exhibiting nearly identical waveform patterns, are consistent with the visual observations that spallation was composed of several discrete fracture events.

Accordingly, the events in Figures 5 and 6 were examined for similar waveform patterns and correlated times of arrival (location), as discussed above. Those marked on the figures had been classified as sequential, correlated events coming from the same location and are labeled as to the total time and number for each event packet. Thus some spalled regions may have been made up of only 2 or 
as high as 82 events. The total time for a given packet divided by the number of corresponding events averaged out to be $0.1 \mathrm{~s}$ for the 103-2 Y sample (Figure 5) and $0.3 \mathrm{~s}$ for 105-2 Y sample (Figure 6).

Spalling morphology. The spalling morphology and macrostructure of the AE specimens is shown in figures $8-11$. Each figure presents about $1.0 \mathrm{~cm}^{2}$ of the specimen surface, before and after immersion, for both as-received and hydrogen annealed samples of the same alloy. After cooldown, the amount of spalling for the as-received samples is noticeably higher than the corresponding hydrogen annealed samples, and only small 'specs' of spalling to bare metal are visible on the hydrogen annealed samples. The amount of subsequent moisture-induced spallation is also much greater for the as-received samples compared to the hydrogen annealed samples. This effect was most noticeable for the as-received $53 \mathrm{Y}$ alloy that had been immersed soon after cool-down.

These trends are in basic agreement with the $\mathrm{AE}$ results, even though the weight change data is not always in direct accord for the reasons discussed previously. A further attempt to quantify these immersion effects was made by counting the number of spall regions. The number of spall segments per $\mathrm{cm}^{2}$ for the various coupons, before and after immersion, are summarized in Table I. The as-received samples generally exhibited more spalling due to immersion than did the hydrogen annealed samples. (The immersion effect for some alloys, e.g. 0 Y, is masked by the production of large spall regions, with a decrease in the apparent number of contiguous segments).

Also shown in Table I are the relative amounts of spalled area determined from image analysis of macrographs such as those in Figures 7-10. Hydrogen annealing reduced the amount of spalling to bare metal after cooling to much less than that for the as-received values, generally to levels below $1 \%$ of the specimen area. Similarly, water immersion can dramatically increase the amount of spallation for the asreceived samples (up to $25 \%$ of the area, $9 \%$ averaged overall), but only occasionally for the hydrogen annealed ones (as low as $0 \%$, and $3 \%$ on average). This area data is a more reliable and direct measure of moisture-induced spalling than is weight change or the number of spall segments.

It is nevertheless instructive to present a graphic overview of all the spalling data as summarized in Figure 12 for weight change, spall segments, and spall area. For each bar chart, the first pair of bars represent data for as-received samples, the other pair is for hydrogen annealed samples. The first bar of 
each pair is for undoped samples, the second represents the average of all the Y-doped samples. Bar shading illustrates the difference between as-cooled and water immersed values. For the most part, consistent overall trends are observed for each measure of as-cooled or immersion-induced spalling: Ydoping reduces spalling greatly, but only for as-received samples; hydrogen annealing reduces spalling especially for undoped but also for Y-doped samples.

Ideally, one would expect the AE data obtained during immersion to be somewhat correlated with all these measurements of moisture-induced spalling. For reasons discussed above, the AE response should most directly correspond to the moisture-induced increase in spall area, as shown in Figure 13. In general this was true, the lower responses (and areas) correlating with hydrogen annealed samples and the higher responses (and areas) with as-received samples. One sample, though, presents a notable exception. Upon immersion, the hydrogen annealed 53-Y sample shows a relatively high AE response in comparison to other annealed samples, but little weight change and no change in spall area (cf., Table II and Figure 8). It is believed that a different procedure for attaching the detectors to the sample may be the cause of this anomaly. (i.e., a higher clamping pressure was used, which would have the effect of amplifying the AE signals). Also, more edge spalling was observed for this sample which was not recorded in the macrographs of the major surfaces. Increased thru-cracks, without spalling, are theoretically possible, but unlikely.

The lack of any systematic trend with $\mathrm{Y}$ content (except as related to the undoped $0 \mathrm{Y}$ alloy) has been discussed in the accompanying paper [2]. Basically, even the lowest Y level was sufficient to provide a considerable amount of scale adhesion, as implied by the lack of desulfurization for all the $\mathrm{Y}$ levels during hydrogen annealing. There is also a possibility that decarburization played a secondary role in adhesion. The susceptibility of the sulfur-free undoped sample to immersion-induced spalling at 500 hr. suggests that a second order adhesion factor may be now be operative.

Table III summarizes the cyclic oxidation weight change (at $1000 \mathrm{hr}$ ) and cumulative weight losses due to immersion (at 500 and $1000 \mathrm{hr}$ ) for four groups of alloys with varying yttrium, sulfur, and carbon content. It can readily be seen that the vast improvement due to hydrogen annealing the undoped alloy was accompanied by sulfur removal to below the detectability limit ( $0.01 \mathrm{ppmw})$. The more modest 
but significant improvement for hydrogen annealing the Y-doped samples (shown as averages of nine alloys) occurred without bulk sulfur removal. However both doped and undoped sample sets exhibit considerable decarburization due to hydrogen annealing. The second order improvement seen for hydrogen annealing the Y-doped samples may thus be associated with carbon removal. The grouping of overall weight change behavior with either as-received or hydrogen annealed carbon levels can be seen in the scatter plot of Figure 14. However no trend in spallation with carbon content is discerned within each alloy group, for carbon contents ranging between 20-150 ppmw $\mathrm{C}$ for the annealed samples and between 300-650 ppmw C for the as-received samples.

\section{DISCUSSION}

Moisture effects, bulk alumina, and alumina interfaces. The accelerating effect of moisture on crack velocity in bulk oxide ceramics is well established. It has been shown that moist environments increase the slow (subcritical) crack growth rate in bulk alumina in static or dynamic "fatigue" tests [16 20]. In tests where a precracked double cantilever beam sample was loaded in air containing various moisture contents, the crack velocity first increased with both $\% \mathrm{H}_{2} \mathrm{O}$ and load (region I), then was only $\% \mathrm{H}_{2} \mathrm{O}$ dependent and load independent (region II), and finally was only load dependent and $\mathrm{H}_{2} \mathrm{O}$ independent (region III) [16]. In the first two stress regimes, it was postulated that a chemical dissolution-type process was rate controlling for the advancement of the crack, i.e., stress-activated in region I and diffusion controlled in region II. In these regimes where the moisture content is important to the crack growth rate, the measured rates approach a maximum on the order of $4 \times 10^{-5} \mathrm{~m} / \mathrm{s}$ for $50 \%$ relative humidity and $10^{-3} \mathrm{~m} / \mathrm{s}$ in liquid water) $[16,20]$. The possible connection between these phenomena in bulk alumina and interfacial alumina scale spallation was originally pointed out for the effects of moisture and water immersion on delayed spallation for $\mathrm{NiAl}$ and $\mathrm{NiCrAl}$ oxidation $[21,3]$.

There are also a number of published studies directed at slow crack growth at metal-alumina interfaces and which have determined values of interface toughness, $\Gamma_{\mathrm{i}}[22-26]$. There is also an implicit or explicit relationship between toughness and moisture (in air) or sulfur segregation. Some pertinent 
aspects and results are summarized in Table IV for comparison to the present study. The first two studies measured the interfacial fracture toughness of $\mathrm{Au} / \mathrm{Al}_{2} \mathrm{O}_{3}$ and $\mathrm{Ni} / \mathrm{Al}_{2} \mathrm{O}_{3}$ interfaces. The toughness decreased to $10 \mathrm{~J} / \mathrm{m}^{2}$ when tested in moist air, compared to 60 and $\geq 100 \mathrm{~J} / \mathrm{m}^{2}$, respectively, when tested in dry $\mathrm{N}_{2}[22,23]$. A stress corrosion mechanism was operative. Carbon was identified as an interface contaminant. In similar $\mathrm{Ni}(\mathrm{Cr}) / \mathrm{Al}_{2} \mathrm{O}_{3}$ samples, with a uniformly high level of sulfur segregation (3\%), moisture actually allowed delamination to occur without an applied stress [24]. An interface toughness of 2-7 $\mathrm{J} / \mathrm{m}^{2}$ was estimated. For samples having only localized low sulfur segregation, the interface toughness was very high $\left(\geq 300 \mathrm{~J} / \mathrm{m}^{2}\right)$, interfacial debonding occurred only in these localized areas, forcing global fracture mainly within the $\mathrm{Al}_{2} \mathrm{O}_{3}$ layer [24].

The remaining three studies in Table IV all deal with some form of delayed failure in thermally grown alumina scales. The first characterized localized buckle growth in the scale for different residual stresses in scales of different thickness on samples of varying thickness [25]. The second monitored scale buckling as a function of applied stress [26]. And the third observed buckling of a thermal barrier coating as a result of localized alumina scale delamination over a period of days [5]. All three were performed at room temperature in ambient air after oxidation and cooldown, and all three yielded estimates of the interface toughness of $\sim 9 \mathrm{~J} / \mathrm{m}^{2}$. An effect of ambient humidity was implied, though not specifically tested. It is not clear why the same toughness values were produced for $\mathrm{Y}$ - or $\mathrm{Zr}$-doped systems as for the undoped system or why these values are much lower than those measured for bulk alumina interfaces $\left(100-300 \mathrm{~J} / \mathrm{m}^{2}\right)$ without sulfur or under $\mathrm{N}_{2}$. The crack velocities were estimated from measurements of buckle size and observation time are also seen to be relatively small. However it is noted that in [26] the buckles often show a near instantaneous 'pop-in' or jump to a $10-20 \mu \mathrm{m}$ radius in $1 / 30 \mathrm{~s}$ or less (the minimum detection time). And the slow growth observed in [5] is often followed by abrupt increases and physical spallation of the scale.

Implications of spalling, immersion, and AE data. The overall response of our four data sets is summarized in III. The as-received, un-doped sample exhibited poor adhesion, accelerated wearout, and susceptibility to water immersion in concert with the well-established sulfur effect on scale adhesion. 
Hydrogen annealing produced an extremely low S content in the un-doped sample, but also reductions in the carbon content. Cyclic behavior was now excellent, but some immersion-induced spallation occurred at $500 \mathrm{hr}$. Y-doping was also very effective, due to gettering and immobilizing $\mathrm{S}$, but some spallation and weight loss persisted. Hydrogen annealing the doped samples improved this behavior without measurably reducing the bulk sulfur content. Assuming that $\mathrm{S}$ was already neutralized by $\mathrm{Y}$, this secondorder improvement may be associated with decarburization. There are thus some qualitative similarities and differences with the interfacial crack growth studies discussed above and listed in Table IV. However, it should be noted that low carbon content or decarburization is neither necessary or sufficient to provide optimum $\mathrm{Al}_{2} \mathrm{O}_{3}$ scale adhesion in a global context [27].

For spallation of the relatively adherent scales formed on these samples, visual, audible, and $\mathrm{AE}$ observations suggest that the spalling process consisted of a number of consecutive fast fracture events. There is no way to ascertain from the present data whether slow crack growth had not occurred before the observable spalling event and associated $\mathrm{AE}$ response. Higher moisture contents have been observed to dramatically increase the crack growth rates $[16,20]$, making it difficult to discriminate between subcritical crack growth and fast fracture. Nevertheless, the AE response was not a constant stream of activity, but a series of individual events. This implies that spallation was a multi-step fracture process that lasted up to a number of seconds in a specific location.

The spalling patterns in Figures 8-11 indicate irregular segment boundaries and examples of both small isolated spall segments and larger regions of contiguous spall segments. The observed process never entailed a gradual delamination of one large segment attached to the sample. Either individual segments popped off or larger portions of metal were exposed by sequential spallation of adjacent segments. This process seems to differ from some elements of more well-controlled, slow crack or buckle growth described in the previous section.

The spalling behavior due to immersion is not entirely different from that observed just on cooldown for moderately adherent scales in ambient air humidity. However it is noticeably different from the behavior of very non-adherent scales on $\mathrm{NiAl}$ or $\mathrm{MCrAl}$ alloys, where a high sulfur content, often coupled with a single isothermal oxidation interval, has been observed to produce a single large flake of 
spalled oxide. The latter instances appear related to extremely weak interfaces that spall completely, with or without the presence of moisture. Thus a spectrum of moisture effects can be envisioned: complete spallation can result from very weak interfaces without moisture (sulfur segregation, no Y-doping); moisture-assisted partial spallation is most apparent for moderately strong interfaces (partially desulfurized); and very little moisture effects or spallation occur for very strong interfaces (hydrogen annealed or Y-doped alloys) [7].

Chemical considerations and model. The synergistic detrimental effect of moisture and sulfur is not well defined. While $\mathrm{SiO}_{2}$ and $\mathrm{Al}_{2} \mathrm{O}_{3}$ bond deterioration has been described for bulk ceramics in the presence of $\mathrm{H}_{2} \mathrm{O}$ by dissolution or bond separation at the crack tip, there are less detailed models of the effect of moisture on oxide-metal bonding. The following observations may be relevant here: (1) Quantum chemical models of $\mathrm{S}$ (and C) at Ag- or Al-MgO [28] and $\mathrm{Ni}_{-} \mathrm{Al}_{2} \mathrm{O}_{3}$ interfaces [29] usually indicate bond stretching and weakening. (However interfacial $\mathrm{C}$ is predicted to actually strengthen $\mathrm{Al}-$ $\mathrm{MgO}$ bonding [28]). (2) Surface science studies of Fe substrates have found that interfacial sulfur can produce $\mathrm{SO}_{2}$ and bond disruption between $\mathrm{Fe}$ and an $\mathrm{Fe}$-oxide monolayer [30]. Water vapor resulted in $\mathrm{SO}_{2}$ evolution from sulfur adsorbed on the outer surface of the Fe-oxide monolayer. In related studies of an $\mathrm{Fe}-\mathrm{S}-\mathrm{Al}_{2} \mathrm{O}_{3}$ monolayer interface, destabilization of the oxide was found, implying S-induced attack of Al-O interface bonds [31]. (3) Aqueous electrochemical studies have shown that sulfur is detrimental to corrosion resistance, yielding higher corrosion currents and wider regimes of the active corrosion potential in the presence of adsorbed sulfur [32]. This de-passivating effect of sulfur has been described as site competition between sulfur and adsorbed $(\mathrm{OH})^{-}$radicals that are normally needed for passive oxide formation.

Although the above phenomena are pertinent, none necessarily imply that moisture should always have a negative synergistic chemical effect with sulfur on oxide-metal bonding or scale spallation. A comprehensive chemical model by which moisture degrades the alumina-metal bond, particularly in the presence of sulfur segregation, is not available. However there does appear to be some basis that sulfur and carbon affect the interfacial bond strength and stability. Since stress corrosion in bulk alumina suggests $\mathrm{Al}-\mathrm{O}$ bond breaking to form $\mathrm{Al}-(\mathrm{OH})^{-}$and since models of $\mathrm{S}$ at alumina-metal interfaces indicate 
bond stretching and weakening, the combined effect, under large 3-4 GPa thermal stresses [33], may be to allow more $\mathrm{H}_{2} \mathrm{O}$ ingress at sulfur-contaminated interface regions. This, in turn, allows weak $\mathrm{Al}-(\mathrm{OH})$ bonds to form more readily, reducing the interfacial toughness which then allows spalling.

A somewhat modified picture of interfacial corrosion fatigue is therefore offered in the simple schematic of Figure 15. Here selective paths for the ingress of water molecules are enabled. These paths may be regions of preferential segregation of sulfur, resulting in stretched and weakened oxide-metal bonds. Some limited residual free sulfur may be available in the near-surface of even the Y-doped asreceived samples. In many cases the spalled regions are aligned with the direction of crystal growth and follow microstructural features (dendrite boundaries) that may serve as preferential diffusion paths for sulfur. The primary disruptive process is thus established during an incubation period, ahead of any planar crack growth front. It is not necessary that a discreet interfacial subcritical crack be growing, but only that local weakening occurs due to the synergistic effect of moisture and sulfur.

The weakening can be defined as a reduction in interface toughness or surface energy of the parted surfaces. When enough of the region is weakened and can no longer support the stored strain energy of that volume of oxide, the affected area spalls off instantaneously. Thus, moisture-assisted delamination here may really just be a fast crack propagation phenomenon, where the decrease in the stored compressive strain energy (thermal expansion mismatch) is greater than the increase in surface energy created by delamination, as described by Clarke et al. and Janakiraman et al. [5, 7]. That is to say, fast fracture and spalling is triggered by a reduction in $\Gamma_{\mathrm{i}}$. Whether or not spalling is preceded by the growth of a subcritical crack, undetected by $\mathrm{AE}$, cannot be unequivocally concluded by the present study. However the rapid succession of numerous AE events from the same location suggests that conventional slow crack growth is not operative.

\section{SUMMARY}

It has been shown that water immersion causes additional spallation at the oxide-metal interface for both Y-doped and undoped Rene'N5, oxidized at $1150^{\circ} \mathrm{C}$ for 500 and $1000 \mathrm{hr}$. Weight change, the 
number and areas of spalled segments, and acoustic emission has been used to demonstrate this result. In most instances, the amount of interfacial spallation, either in the as-cooled condition or after water immersion, was considerably lower for samples that had been hydrogen annealed. While desulfurization is the obvious explanation for the undoped alloy, no conclusive explanation could be claimed for Ydoped alloys because here the bulk sulfur content had not been reduced. Decarburization due to hydrogen annealing may partially explain this benefit, as a detrimental synergy between moisture and carbon segregation had been suggested in previous metal-oxide interfacial toughness studies.

It was also demonstrated that a considerable stabilization effect occurred by retaining samples for 1 year before immersion, which decreased the effect of immersion considerably. After incubation times ranging from seconds to many hours, spalling by immersion was observed to be a succession of nearinstantaneous events accompanied by the release of considerable acoustic energy. The crack growth rate of a spalled segment was estimated from the acoustic emission response and segment size to be at least $10^{-3} \mathrm{~m} / \mathrm{s}$ and possibly as high as $20 \mathrm{~m} / \mathrm{s}$. This is considerably higher than slow crack growth rates usually reported for static corrosion fatigue processes in bulk ceramics. A detrimental synergy between moisture and sulfur (plus possibly carbon) and moisture is implied by the results. It is proposed that, simplistically, impurity segregation sensitizes the interface by increasing the interfacial bond distance, thus allowing greater access by molecular $\mathrm{H}_{2} \mathrm{O}$, decreased toughness, and spalling.

$* * * * * * * * * * * *$

\section{REFERENCES}

1. B.K. Tubbs and J.L. Smialek: "Effect of Sulfur Removal on Scale Adhesion to PWA 1480," Corrosion and Particle Erosion at High Temperatures, V. Srinivasan, K. Vedula, eds., TMS-AIME, pp. 459-487 (1989).

2. J.L. Smialek and B.A. Pint: "Optimizing Scale Adhesion on Single Crystal Superalloys," in $5^{\text {th }}$ International Symposium on High Temperature Corrosion, R. Streiff, et al., eds., European 
Federation of Corrosion, Les Embiez, France, 2000, Trans Tech Publications, Materials Science Forum, in press. (NASA TM 2000-210362, August, 2000),

3. J. L. Smialek: "Adherent $\mathrm{Al}_{2} \mathrm{O}_{3}$ Scales Formed on Undoped $\mathrm{NiCrAl}$ Alloys," in N. L. Peterson Mem. Symp. Proc. on Oxidation and Associated Mass Transport, TMS-AIME Oct. 6-9, pp. 297-313 (1986).

4. M.A. Smith, W.E. Frazier, and B.A. Pregger, Mat. Sci. and Engineer., 203, 388 (1995).

5. V. Sergo and D.R. Clarke, J. Am. Ceram. Soc., 1ㅣ, pp. 3237-3242 (1998).

6. J.L. Smialek, J.A. Nesbitt, C.A. Barrett, and C.E. Lowell: "Cyclic Oxidation Testing and Modelling: a NASA Lewis Perspective," in Cyclic Oxidation of High Temperature Materials, M. Schutze and W.J. Quadakkers, eds., European Federation of Corrosion, Institute of Materials, London, pp. 148168, (1999). (Also NASA TM 2000-209769, February 2000).

7. R. Janakiraman, G.H. Meier, and F.S. Pettit: "The Effect of Water Vapor on the Oxidation of Alloys that Develop Alumina Scales for Protection," in Cyclic Oxidation of High Temperature Materials, M. Schutze and W.J. Quadakkers, eds., European Federation of Corrosion, Institute of Materials, London, pp. 38-62, (1999).

8. C. Coddet, G. Beranger, and J. Chretien: "Application of the Acoustic Emission Technique to the Detection of Oxide Layer Cracking During the Oxidation Process", in Materials and Coatings to Resist High Temperature Corrosion, eds. D.R. Holmes and A. Rahmel, Applied Science Publishers Ltd., London, pp. 175-183 (1978).

9. A. Ashary, G.H. Meier, and F.S. Pettit: "Acoustic Emission Study of Oxide Cracking During Alloy Oxidation", in High-Temperature Protective Coatings, S.C. Singhal, ed., AIME, pp. 105119 (1982).

10. A.S. Khanna, H. Jonas, W.J. Quadakkers, Werkstoffe und Korrosion, $\underline{40}$, pp. 552-558 (1989).

11. W. Christl, A. Rahmel, and M. Schutze, Oxidation of Metals, 31, pp. 35-69 (1989).

12. F. Dettenwanger, H. Echsler, C. Bruns, and M. Schutze: "Investigation of Damage Mechanisms in Thermal Barrier Coatings by Acoustic Emission", in Elevated Temperature Coatings: Science and Technology III, J.M. Hampikian and N.B. Dahotre, eds., TMS, pp. 39-48 (1999). 
13. G. N. Morscher, Comp. Sci. Techn., $\underline{59}$, pp. 687-697 (1999).

14. W.H. Prusser, et al, Mat. Eval., 9, 1052-1058, (1995).

15. M. R. Gorman, J. Acoust. Soc. Am., 90, pp. 358-364 (1991).

16. S.M. Weiderhorn, Intl. J. Fract. Mech., 4, pp. 171-177 (1968).

17. J.E. Ritter and J.N. Humenik, J. Mat. Sci., 14, pp. 626-632 (1979).

18. M. Nagabhooshanam and V.R. Dunke, J. Mat. Sci., 27, pp. $2377-2382$ (1992).

19. D.M. Kotchick and R.E. Tressler, J. Mat. Sci., 10, pp. 608-612 (1975).

20. M.E. Ebrahami, J. Chevalier, and G. Fantozzi, J. Mater. Sci., 15, pp.142-147 (2000).

21. J. L. Smialek, Met. Trans., 9A, pp. 309-320 (1978).

22. X. Mao and A.G. Evans, submitted to Acta Mater.

23. F.G. Gaudett, S.Suresh, A.G.Evans, G. Dehm, and M. Ruhle, Acta Met., 45, pp. 3503-3513, (1997).

24. F.G. Gaudette, S. Suresh, and A.G. Evans, Metall. Mater. Trans., 31A, pp. 1977-1983 (2000).

25. V.K. Tolpygo and D.R. Clarke, Mat. Sci. Eng., A278, pp. 142-161, (2000).

26. J.S. Wang and A.E. Evans, Acta mater., 46, pp. 4993-5005, (1998).

27. J.L. Smialek, Oxid. Met., $\underline{55}$, pp. 75-86, (2001).

28. T. Hong, J.R. Smith, and D.J. Srolovitz, Acta metall. mater., 43, pp. 2721-2730 (1995).

29. S.Y. Hong, A.B. Anderson, J.L. Smialek, Surf. Sci., 230, pp.174-183 (1990).

30. H. Cabibil and J.A. Kelber, Surf. Sci., $\underline{373}$, pp. 257-274 (1997).

31. I. Chen et al., Oxid. Met., 54, pp. 285-300 (2000).

32. P. Marcus and J. Oudar: "Surface Modification by Chemisorbed Sulfur," in Fundamental Aspects of Corrosion Protection by Surface Modification, E. McCafferty, C.R. Clayton, and J. Oudar, eds., Electrochem. Soc., Pennington, N.J., pp.173-193 (1979).

33. D.R. Clarke, R.J. Christensen, and V. Tolpygo, Surf. And Coat. Technol., 94-95, pp. 89-93, (1997). 
Table I. Summary of immersion effects on spall weight, number of spall segments, and relative spall areas for Rene' $\mathrm{N} 5$ oxidized at $1150^{\circ} \mathrm{C}$ for 10001 -hr cycles. (average of all Y-doped samples shown at the bottom of each column). A) as-received samples; B) hydrogen annealed samples.

Table II. Comparison of moisture-induced AE response (number and energy of events) with moistureinduced weight loss, increase in number of spall segments, and increase in $\%$ of spalled area. Samples 53 Y tested immediately after oxidation; all others immersed approximately $1 \mathrm{yr}$. later.

Table III. Correlation between Rene'N5 sample chemistry and spallation behavior. (Dopant and impurity analyses from GDMS; weight change $\Delta \mathrm{W}_{1000}$ after oxidation for 10001 -hr cycles at $1150^{\circ} \mathrm{C}$; summed $\left(\Sigma \Delta \mathrm{W}_{\mathrm{H}_{2} \mathrm{O}}\right)$ weight losses from 500 and $1000 \mathrm{hr}$ immersions).

Table IV. Some effects of moisture or contaminants on interface toughness measured for artificial and thermally grown alumina-metal interfaces. (see text for explanation). 


\section{Figure Captions}

1. Additional weight loss due to water immersion for Rene' $\mathrm{N} 5$ oxidized at $1150^{\circ} \mathrm{C}$ for $500 \mathrm{l}$-hr cycles. (note large beneficial effect of hydrogen annealing).

2. Additional weight loss due to water immersion for Rene' $\mathrm{N} 5$ oxidized at $1150^{\circ} \mathrm{C}$ for 10001 -hr cycles. (note occasional beneficial effect of hydrogen annealing).

3. Acoustic emission response during water immersion for alloy $53 \mathrm{Y}$; Rene' $\mathrm{N} 5$ oxidized at $1150^{\circ} \mathrm{C}$ for 1000 1-hr cycles; squares=as-received, circles= $\mathrm{H}_{2}$-annealed. (note major beneficial effect of hydrogen annealing).

4. Acoustic emission response during water immersion for alloy $88 \mathrm{Y}$; Rene'N5 oxidized at $1150^{\circ} \mathrm{C}$ for 1000 1-hr cycles; squares=as-received, circles $=\mathrm{H}_{2}$-annealed. (note moderate beneficial effect of hydrogen annealing).

5. Acoustic emission response during water immersion for alloy $103 \mathrm{Y}$; Rene'N5 oxidized at $1150^{\circ} \mathrm{C}$ for 10001 -hr cycles; squares $=$ as-received, circles $=\mathrm{H}_{2}$-annealed. (note significant beneficial effect of hydrogen annealing).

6. Acoustic emission response during water immersion for alloy $105 \mathrm{Y}$; Rene'N5 oxidized at $1150^{\circ} \mathrm{C}$ for 10001 -hr cycles; squares $=$ as-received, circles $=\mathrm{H}_{2}$-annealed. (note significant beneficial effect of hydrogen annealing).

7. Acoustic emission waveforms corresponding to consecutive individual events, $\mathrm{A}$ and $\mathrm{B}$, as received by two sensors at different ends of the sample. For immersion of alloy 103 Y, Rene'N5 
oxidized at $1150^{\circ} \mathrm{C}$ for 10001 -hr cycles, as-received sample.

8. Surface spallation appearance of alloy $53 \mathrm{Y}$ before and after water immersion; Rene'N5 oxidized at $1150^{\circ} \mathrm{C}$ for 10001 -hr cycles; (A,B) as-received; (C,D) $\mathrm{H}_{2}$-annealed. (note considerable immersion effect for as-received sample and minimal spallation for $\mathrm{H}_{2}$-annealed sample).

9. Surface spallation appearance of alloy $88 \mathrm{Y}$ before and after water immersion; Rene'N5 oxidized at $1150^{\circ} \mathrm{C}$ for 1000 1-hr cycles; (A,B) as-received; (C,D) $\mathrm{H}_{2}$-annealed. (note slight immersion effect for as-received sample and reduced spallation for $\mathrm{H}_{2}$-annealed sample).

10. Surface spallation appearance of alloy $103 \mathrm{Y}$ before and after water immersion; Rene'N5 oxidized at $1150^{\circ} \mathrm{C}$ for 10001 -hr cycles; (A,B) as-received; (C,D) $\mathrm{H}_{2}$-annealed. (note moderate immersion effect for as-received sample and reduced spallation for $\mathrm{H}_{2}$-annealed sample).

11. Surface spallation appearance of alloy $105 \mathrm{Y}$ before and after water immersion; Rene'N5 oxidized at $1150^{\circ} \mathrm{C}$ for 1000 1-hr cycles; (A,B) as-received; (C,D) $\mathrm{H}_{2}$-annealed. (note moderate immersion effect for as-received sample and reduced spallation for $\mathrm{H}_{2}$-annealed sample).

12. Increase in scale spallation due to water immersion for Rene' $\mathrm{N} 5$ oxidized at $1150^{\circ} \mathrm{C}$ for $10001-\mathrm{hr}$ cycles, showing effects of Y-doping (average data from Table I) and hydrogen annealing. A) specific weight changes; B) number of spall segments; C) relative spall areas.

13. Increasing trends in immersion-induced $\mathrm{AE}$ response with measured immersion-induced spall area for Y-doped Rene'N5 alloys, 53-105, after $1000 \mathrm{hr}$ oxidation at $1150^{\circ} \mathrm{C}$. 
14. Correlation scatter plot of final weight change with carbon content for as-received and hydrogen annealed Rene'N5, oxidized at $1150^{\circ} \mathrm{C}$ for 10001 -hr cycles.

15. Schematic sequence of moisture-induced spallation events. Rapid spallation $\left(\Delta \tau_{\mathrm{sp}}\right)$ preceded by a finite incubation time $\left(\Delta \tau_{\text {inc }}\right)$ of bond-weakening near exposed interfaces. 
Table I

\begin{tabular}{|c|c|c|c|c|c|c|c|c|c|}
\hline & & & & \multicolumn{2}{|c|}{ A) As-Received } & & & & \\
\hline & \multicolumn{3}{|c|}{ weight change, $\mathrm{mg} / \mathrm{cm}^{2}$} & \multicolumn{3}{|c|}{ no. of spall segments $/ \mathrm{cm}^{2}$} & \multicolumn{3}{|c|}{ rel. spall area, \% } \\
\hline Alloy & oxidized & immersed & $\Delta \mathrm{H}_{2} \mathrm{O}$ & oxidized & immersed & $\Delta \mathrm{H}_{2} \mathrm{O}$ & oxidized & immersed & $\Delta \mathrm{H}_{2} \mathrm{O}$ \\
\hline 0 & -40.642 & -42.098 & 1.456 & 104 & 76 & -28 & 5.2 & 22.9 & 17.8 \\
\hline 16 & -0.913 & -1.135 & 0.222 & 70 & 76 & 6 & 2.4 & 6.8 & 4.4 \\
\hline 24 & -0.719 & -0.835 & 0.115 & 54 & 80 & 26 & 1.7 & 4.0 & 2.3 \\
\hline 31 & -1.359 & -1.691 & 0.333 & 60 & 60 & 0 & 1.8 & 26.9 & 25.1 \\
\hline 48 & -0.972 & -1.387 & 0.415 & 80 & 82 & 2 & 2.2 & 8.5 & 6.3 \\
\hline 53 & -0.742 & -1.106 & 0.364 & 28 & 89 & 61 & 0.4 & 16.0 & 15.6 \\
\hline 67 & -1.162 & -1.284 & 0.122 & 31 & 118 & 87 & 0.4 & 3.1 & 2.7 \\
\hline 88 & -1.054 & -1.175 & 0.121 & 56 & 130 & 74 & 1.3 & 6.4 & 5.1 \\
\hline 103 & -1.040 & -1.129 & 0.089 & 41 & 119 & 78 & 1.0 & 4.5 & 3.6 \\
\hline 105 & -0.971 & -1.086 & 0.115 & 50 & 107 & 57 & 1.3 & 7.5 & 6.1 \\
\hline Y Avg: & -0.992 & -1.203 & 0.211 & 52.2 & 95.7 & 43.4 & 1.4 & 9.3 & 7.9 \\
\hline \multirow[t]{4}{*}{ Y $1 \sigma:$} & 0.198 & 0.237 & 0.127 & 17.1 & 23.7 & 35.1 & 0.7 & 7.6 & 7.6 \\
\hline & & & & & & & & & \\
\hline & & & & \multicolumn{2}{|c|}{ B) $\mathrm{H}_{2}$-Annealed } & & & & \\
\hline & & & & & & & & & \\
\hline 0 & 0.797 & 0.710 & 0.087 & 16 & 29 & 13 & 0.12 & 0.3 & 0.1 \\
\hline 16 & 0.821 & 0.599 & 0.222 & 13 & 23 & 10 & 0.18 & 10.5 & 10.3 \\
\hline 24 & 0.703 & 0.463 & 0.24 & 13 & 30 & 17 & 0.31 & 2.7 & 2.3 \\
\hline 31 & 0.711 & 0.096 & 0.616 & 17 & 27 & 10 & 0.26 & 12.2 & 11.9 \\
\hline 48 & 0.638 & 0.531 & 0.107 & 53 & 72 & 19 & 0.82 & 4.1 & 3.3 \\
\hline 53 & 1.014 & 0.987 & 0.027 & 1 & 1 & 0 & 0.01 & 0.0 & 0.0 \\
\hline 67 & 0.932 & 0.864 & 0.069 & 2 & 7 & 5 & 0.01 & 0.4 & 0.4 \\
\hline 88 & 0.684 & 0.578 & 0.107 & 11 & 50 & 39 & 0.12 & 0.9 & 0.7 \\
\hline 103 & 0.895 & 0.813 & 0.082 & 3 & 12 & 9 & 0.07 & 0.3 & 0.2 \\
\hline 105 & 0.799 & 0.676 & 0.123 & 7 & 24 & 17 & 0.11 & 0.4 & 0.3 \\
\hline Y Avg: & 0.800 & 0.623 & 0.177 & 13.3 & 27.3 & 14.0 & 0.21 & 3.5 & 3.3 \\
\hline Y $1 \sigma:$ & 0.127 & 0.261 & 0.178 & 15.9 & 22.0 & 11.2 & 0.25 & 4.7 & 4.6 \\
\hline
\end{tabular}


Table II

\begin{tabular}{|c|c|c|c|c|c|}
\hline $\begin{array}{l}\text { alloy, } \\
\text { (ppm Y) }\end{array}$ & $\begin{array}{c}\mathrm{AE}, \\
\text { (no. events) }\end{array}$ & $\begin{array}{c}\mathrm{AE}, \\
\text { (energy) }\end{array}$ & $\begin{array}{c}\text { weight loss, } \\
\left(\mathrm{mg} / \mathrm{cm}^{2}\right)\end{array}$ & $\begin{array}{l}\text { no. spall } \\
\text { segments }\end{array}$ & $\begin{array}{c}\text { spall area, } \\
(\%)\end{array}$ \\
\hline \multicolumn{6}{|c|}{ A) as-received samples } \\
\hline 53 & 3291 & 17630 & 0.364 & 61 & 15.56 \\
\hline 88 & 193 & 697 & 0.121 & 74 & 5.09 \\
\hline 103 & 74 & 389 & 0.089 & 78 & 3.55 \\
\hline 105 & 161 & 1798 & 0.115 & 57 & 6.13 \\
\hline \multicolumn{6}{|c|}{ B) hydrogen annealed samples } \\
\hline 53 & 211 & 695 & 0.027 & 0 & 0 \\
\hline 88 & 32 & 406 & 0.107 & 39 & 0.74 \\
\hline 103 & 8 & 4 & 0.082 & 9 & 0.21 \\
\hline 105 & 13 & 25 & 0.115 & 17 & 0.31 \\
\hline
\end{tabular}




\section{Table III}

\begin{tabular}{|c|c|c|c|c|c|c|}
\hline & $\begin{array}{c}Y \\
\text { ppmw }\end{array}$ & $\begin{array}{c}\mathrm{S} \\
\mathrm{ppmw}\end{array}$ & $\begin{array}{c}\text { C } \\
\text { ppmw }\end{array}$ & $\begin{array}{l}\Delta \mathrm{W}_{1000} \\
\mathrm{mg} / \mathrm{cm}^{2}\end{array}$ & $\begin{array}{l}\Sigma \Delta \mathrm{W}_{\mathrm{H} 2 \mathrm{O}} \\
\mathrm{mg} / \mathrm{cm}^{2}\end{array}$ & Conclusion \\
\hline $\begin{array}{l}\text { undoped, as-received } \\
\text { undoped, } \mathrm{H}_{2} \text {-annealed }\end{array}$ & $\begin{array}{l}0.3 \\
0.3\end{array}$ & $\begin{array}{c}2.6 \\
<0.01\end{array}$ & $\begin{array}{c}375 \\
95\end{array}$ & $\begin{array}{c}-40.64 \\
0.80\end{array}$ & $\begin{array}{l}-2.15 \\
-0.40\end{array}$ & $\begin{array}{l}\text { poor adhesion due to } \mathrm{S} \text { segregation } \\
\text { excellent adhesion due to } \mathrm{S} \text { removal }\end{array}$ \\
\hline $\begin{array}{l}\text { Y-doped, as received } \\
\text { Y-doped, } \mathrm{H}_{2} \text {-annealed } \\
\text { (avg. of } 9 \text { Y-doped alloys) }\end{array}$ & $\begin{array}{l}20-110 \\
20-110\end{array}$ & $\begin{array}{l}5.0 \\
5.3\end{array}$ & $\begin{array}{l}430 \\
110\end{array}$ & $\begin{array}{l}-0.93 \\
0.82\end{array}$ & $\begin{array}{l}-0.86 \\
-0.21\end{array}$ & $\begin{array}{l}\text { v. good adhesion due to S-gettering } \\
\text { excellent adhesion due to S-gettering, } \\
\text { (and C removal?) }\end{array}$ \\
\hline
\end{tabular}




\section{Table IV}

\begin{tabular}{|c|c|c|c|c|c|c|c|}
\hline System & Test & Pre-exposure & $\begin{array}{l}\text { Segregant/ } \\
\text { Moisture }\end{array}$ & $\begin{array}{c}\Gamma_{1} \\
(\mathrm{~J} / \mathrm{m} 2) \\
\end{array}$ & $\begin{array}{c}v_{c} \\
(\mathrm{~m} / \mathrm{s})\end{array}$ & $\begin{array}{c}\text { Buckle or } \\
\text { spall dia. }(\mu \mathrm{m})\end{array}$ & Reference \\
\hline $\begin{array}{l}\mathrm{Au}-\mathrm{Al}_{2} \mathrm{O}_{3} \text { plates } \\
\text { " " " }\end{array}$ & $\begin{array}{c}\text { DCDC } \\
" ~ " ~\end{array}$ & & $\begin{array}{l}\text { ?/N } \\
\text { ?/air }\end{array}$ & $\begin{array}{l}60 \\
10 \\
\end{array}$ & & & Mao, Evans \\
\hline $\begin{array}{l}\mathrm{Ni}-\mathrm{Al}_{2} \mathrm{O}_{3} \text { plates } \\
" \quad " \quad "\end{array}$ & $\begin{array}{c}\text { 4-pt. bend } \\
\text { " " }\end{array}$ & $\begin{array}{l}1277^{\circ} \mathrm{C} \text { vac. hot press } \\
1277^{\circ} \mathrm{C} \text { vac. hot press }\end{array}$ & $\begin{array}{l}\mathrm{C} / \mathrm{N}_{2} \\
\text { C/air }\end{array}$ & $\begin{array}{c}>100 \\
10\end{array}$ & & & Gaudette et al. (1997) \\
\hline $\begin{array}{l}\mathrm{NiCr}-\mathrm{Al}_{2} \mathrm{O}_{3} \text { plates } \\
\quad " \quad "\end{array}$ & $\begin{array}{c}\mathrm{DCDC} \\
" \|\end{array}$ & $\begin{array}{l}1277^{\circ} \mathrm{C} \text { vac. hot press } \\
1377^{\circ} \mathrm{C} \text { vac. hot press }\end{array}$ & $\begin{array}{c}\text { ?/air } \\
\text { S,C/air }\end{array}$ & $\begin{array}{l}>300 \\
2-7\end{array}$ & & & Gaudette et al. (2000) \\
\hline $\begin{array}{l}\mathrm{Al}_{2} \mathrm{O}_{3} \text { scale on } \\
\text {-FeCrAlZr }\end{array}$ & buckle growth vs $\sigma_{\text {res. }}$ & $0.5-100 \mathrm{hr}$ at $1200^{\circ} \mathrm{C}$ & ?/air & 8.6 & $3 \times 10^{-7}$ (slow) & $150-200$ & Tolpygo, Clarke (2000) \\
\hline $\begin{array}{l}\mathrm{Al}_{2} \mathrm{O}_{3} \text { scale on } \\
\text {-NiAl-superalloy }\end{array}$ & buckle growth vs $\sigma_{\text {app. }}$ & $1-100 \mathrm{hr}$ at $1100^{\circ} \mathrm{C}$ & ?/air & 9 & $5 \times 10^{-4}$ (jump) & $10-30$ & Wang, Evans (1998) \\
\hline $\begin{array}{l}\mathrm{YSZ}-\mathrm{Al}_{2} \mathrm{O}_{3} \text { scale } \\
-\mathrm{NiCoCrAlY}-1484 \\
\end{array}$ & TBC buckle growth & $12 \mathrm{hr}$ at $1121^{\circ} \mathrm{C}$ & ?/air & 9 & $4.6 \times 10^{-12}$ (est.) & $10-150$ & Sergo, Clarke (1998) \\
\hline $\begin{array}{l}\mathrm{Al}_{2} \mathrm{O}_{3} \text { scale on } \\
\text {-Rene'N5 }\end{array}$ & $A E$ response from spall & $1000 \mathrm{hr}$ at $1150^{\circ} \mathrm{C}$ & $? / \mathrm{H}_{2} \mathrm{O}$ & 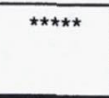 & $\begin{array}{c}1 \times 10^{-3}, 20 \\
\text { (est. min., max.) }\end{array}$ & $200-5000$ & present study \\
\hline
\end{tabular}




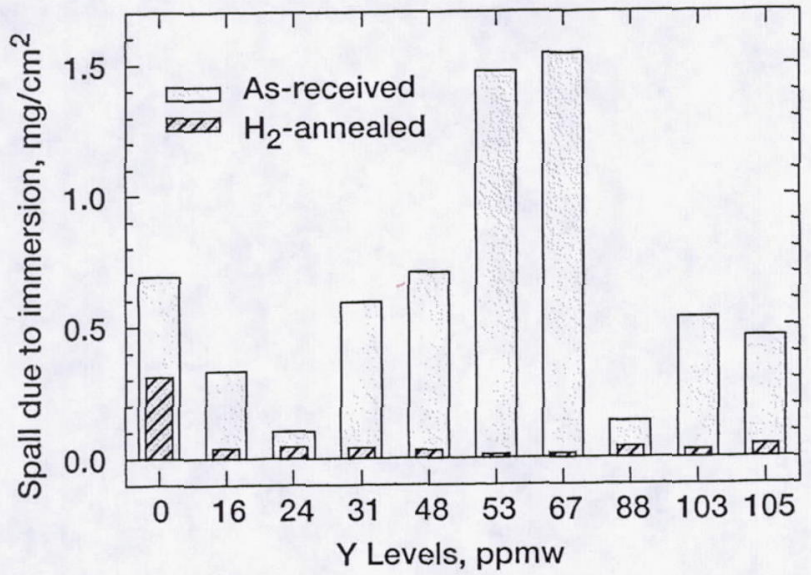

Figure 1.-Additional weight loss due to water immersion for Rene'N5 oxidized at $1150^{\circ} \mathrm{C}$ for 5001 -hr cycles. (Note large beneficial effect of hydrogen annealing). 


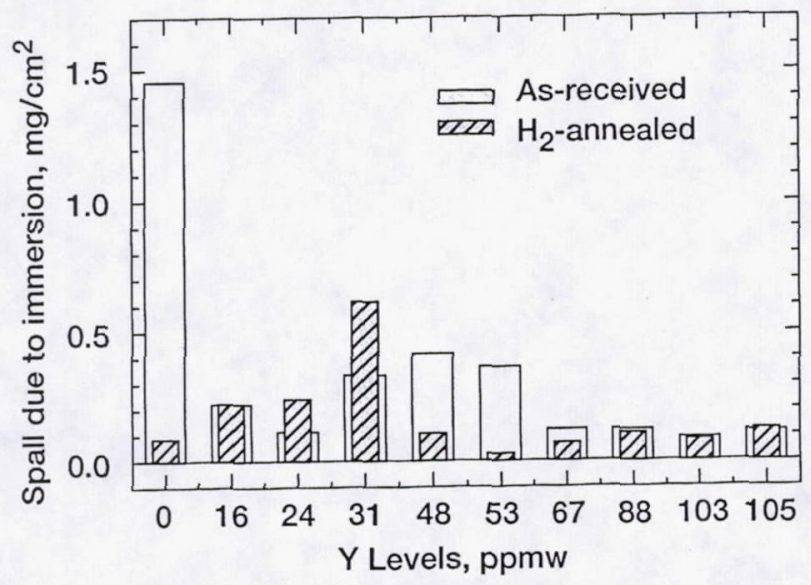

Figure 2.-Additional weight loss due to water immersion for Rene'N5 oxidized at $1150{ }^{\circ} \mathrm{C}$ for 10001 -hr cycles. (Note occasional beneficial effect of hydrogen annealing). 


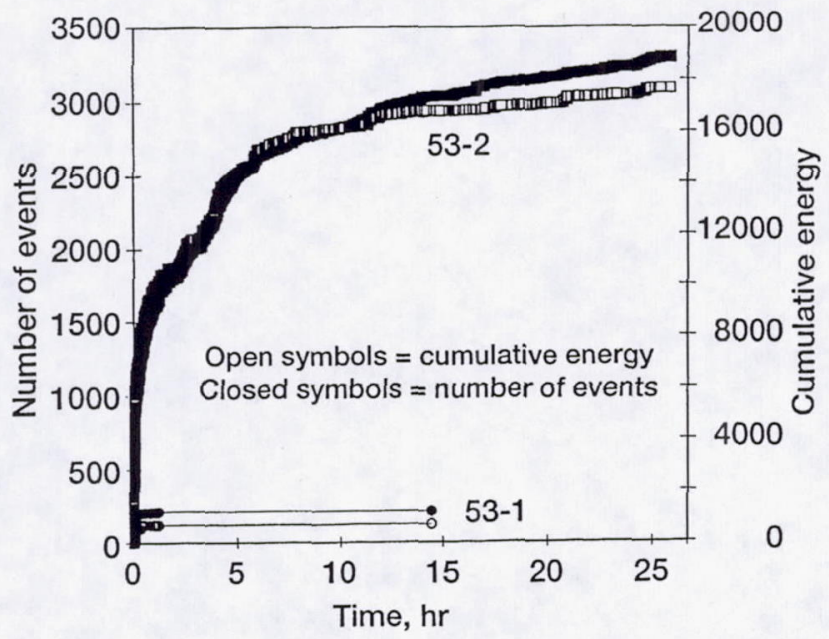

Figure 3.-Acoustic emission response during water immersion for alloy $53 \mathrm{Y}$; Rene'N5 oxidized at $1150{ }^{\circ} \mathrm{C}$ for 10001 -hr cycles; squares = as-received, circles $=\mathrm{H}_{2}$-annealed. (Note major beneficial effect of hydrogen annealing). 


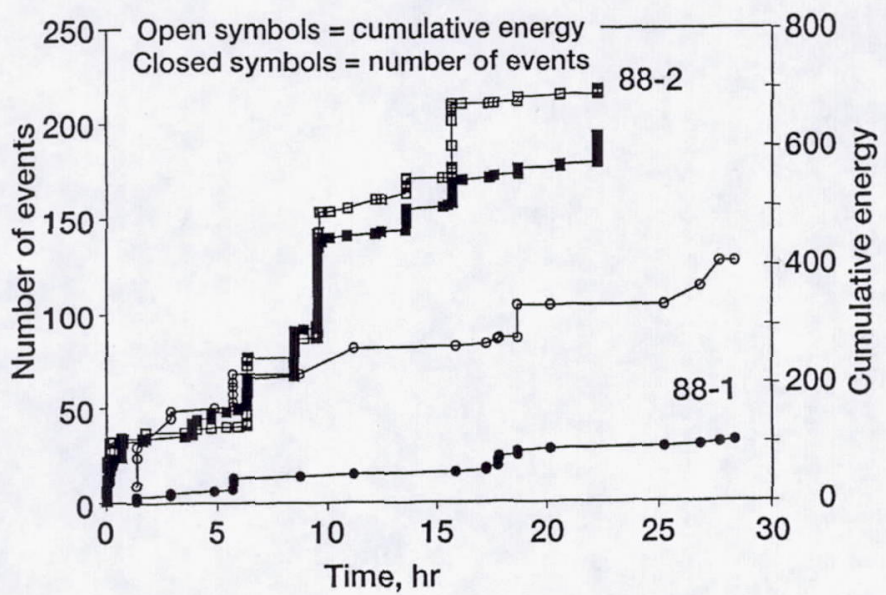

Figure 4.-Acoustic emission response during water immersion for alloy $88 \mathrm{Y}$; Rene'N5 oxidized at $1150^{\circ} \mathrm{C}$ for 1000 1-hr cycles; squares=as-received, circles = $\mathrm{H}_{2}$-annealed. (Note moderate beneficial effect of hydrogen annealing). 


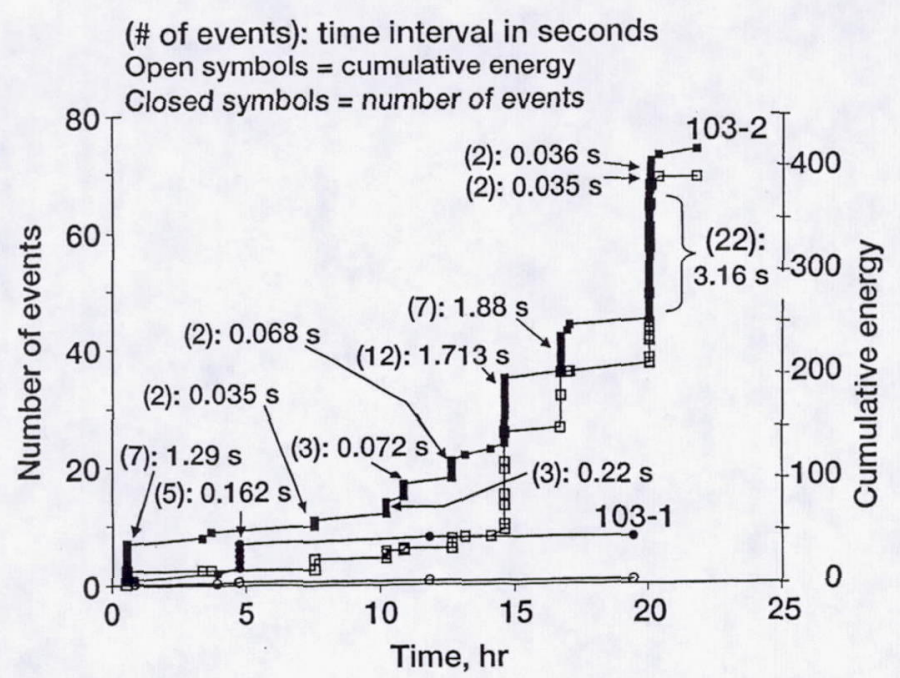

Figure 5.-Acoustic emission response during water immersion for alloy $103 \mathrm{Y}$; Rene'N5 oxidized at $1150^{\circ} \mathrm{C}$ for 10001 -hr cycles; squares = as-received, circles $=\mathrm{H}_{2}$-annealed. (Note significant beneficial effect of hydrogen annealing). 


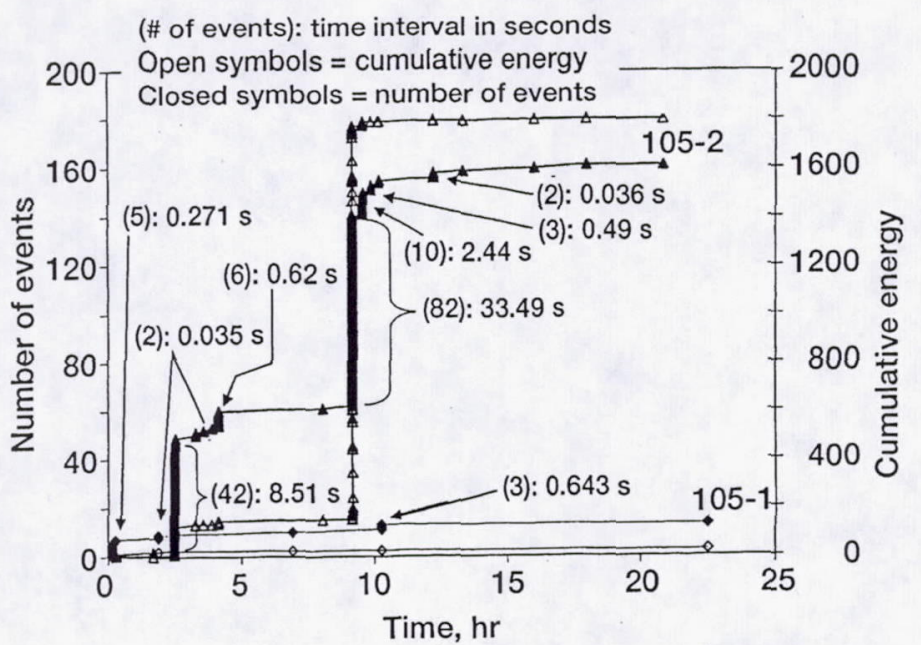

Figure 6.-Acoustic emission response during water immersion for alloy $105 \mathrm{Y}$; Rene'N5 oxidized at $1150^{\circ} \mathrm{C}$ for 10001 -hr cycles; triangles = as-received, diamonds $=\mathrm{H}_{2}$-annealed. (Note significant beneficial effect of hydrogen annealing). 

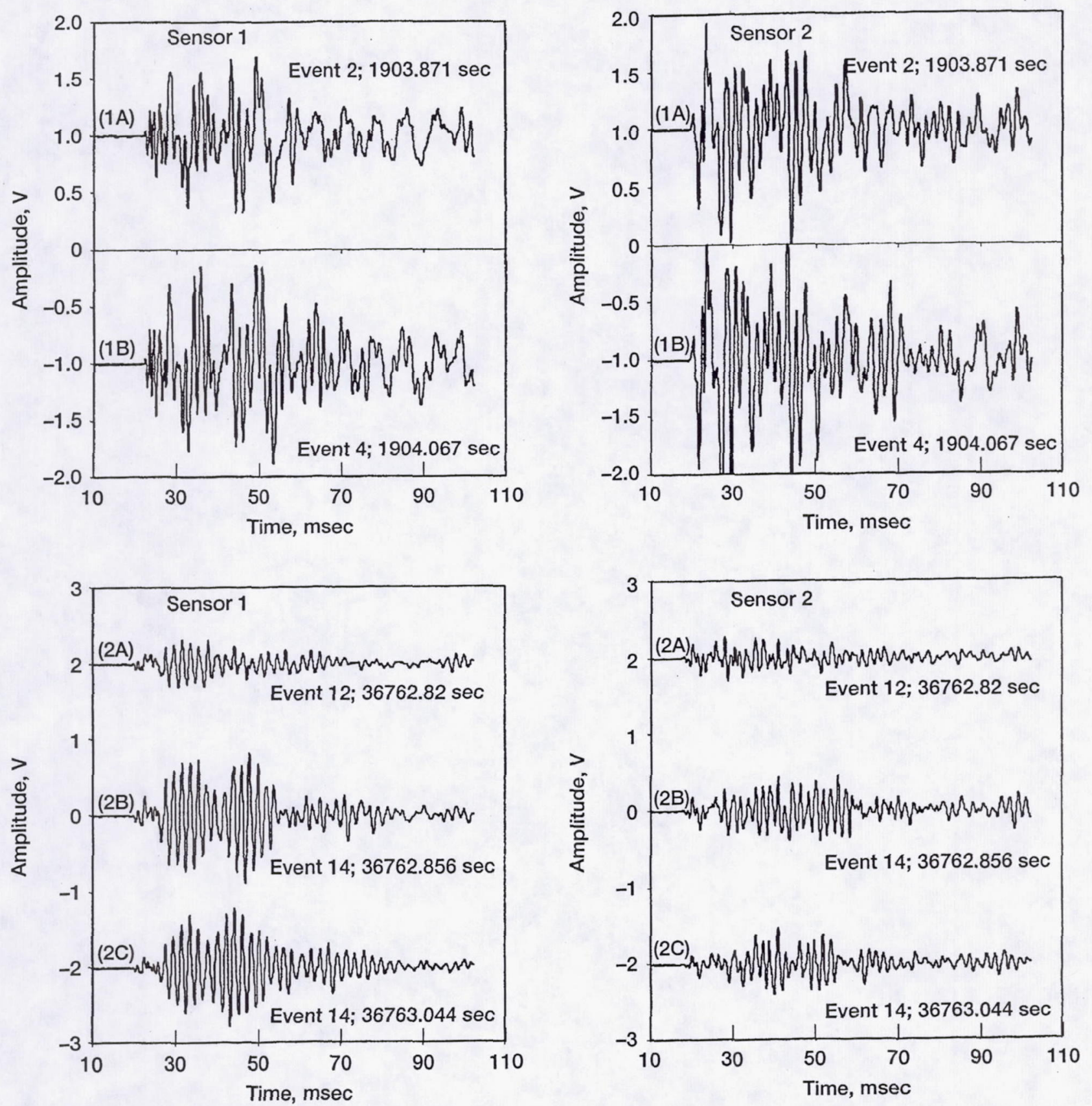

Figure 7.-Acoustic emission waveforms corresponding to consecutive individual events, $A$ and $B$, as received by two sensors at different ends of the sample. For immersion of alloy $103 \mathrm{Y}$, Rene'N5 oxidized at $1150^{\circ} \mathrm{C}$ for 1000 1-hr cycles, as-received sample. 

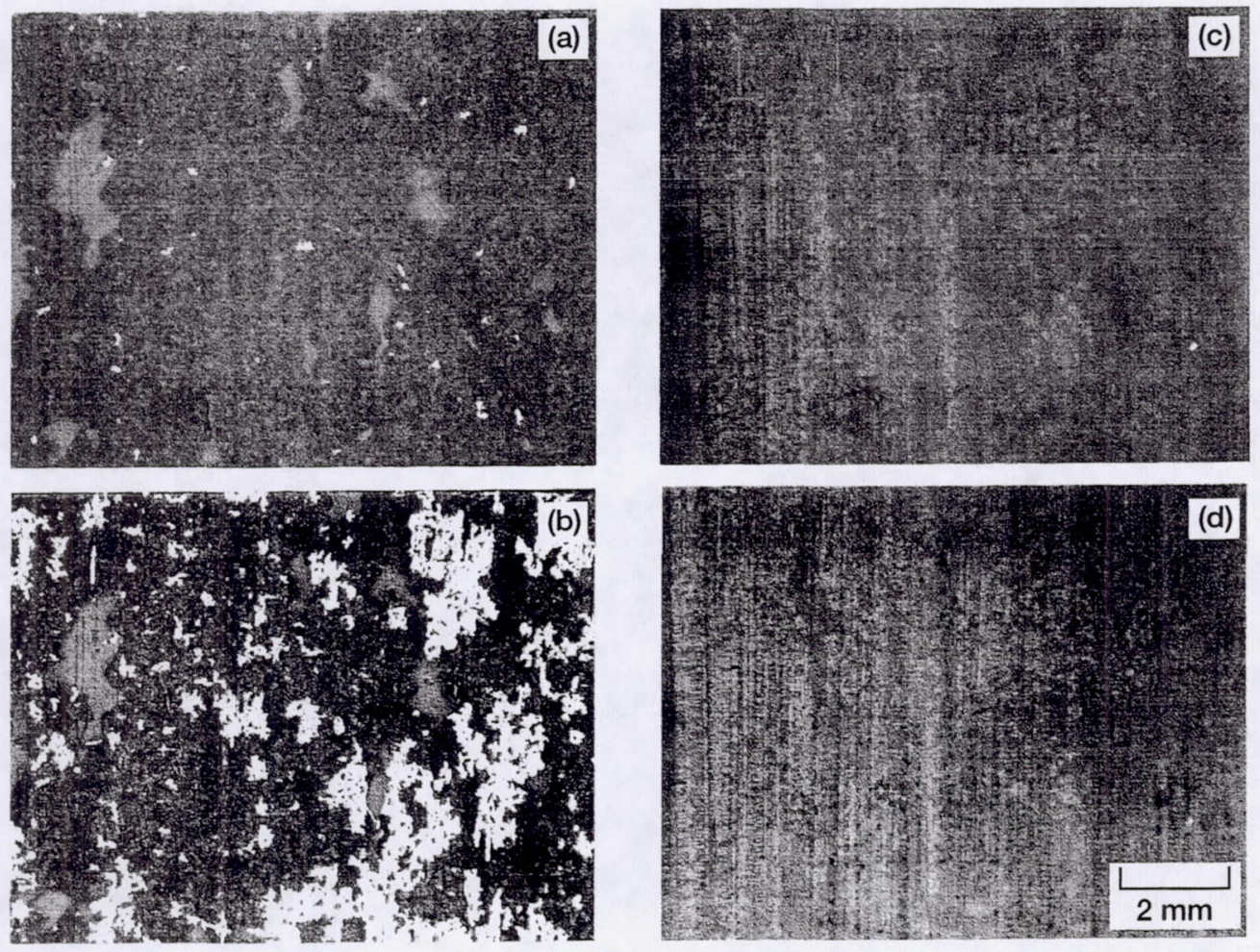

Figure 8.- Surface spallation appearance of alloy $53 \mathrm{Y}$ before and after water immersion; Rene'N5 oxidized at $1150^{\circ} \mathrm{C}$ for 10001 -hr cycles; (a, b) as-received; (c, d) $\mathrm{H}_{2}$-annealed. (Note considerable immersion effect for as-received sample and minimal spallation for $\mathrm{H}_{2}$-annealed sample). 

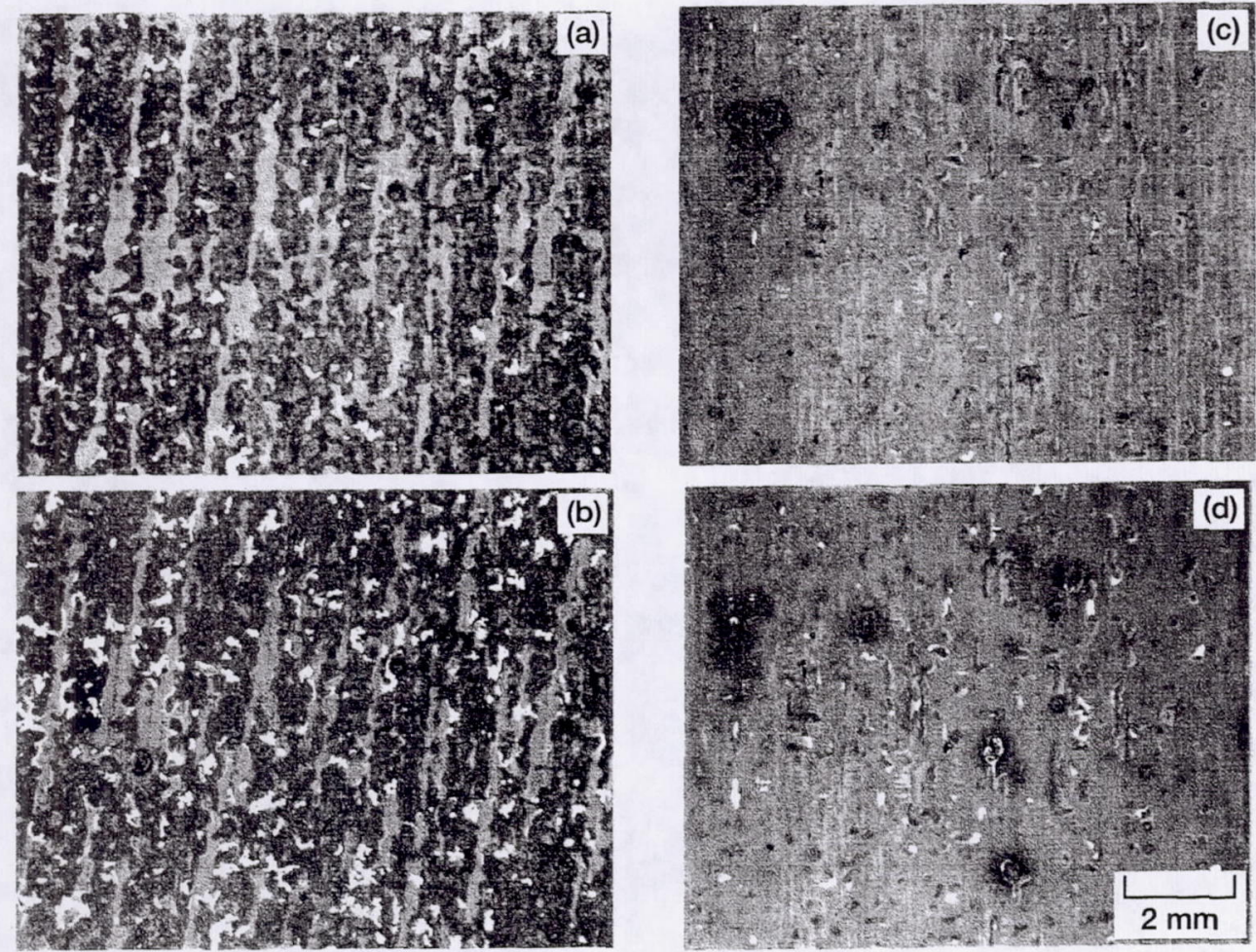

Figure 9.-Surface spallation appearance of alloy $88 \mathrm{Y}$ before and after water immersion; Rene'N5 oxidized at $1150^{\circ} \mathrm{C}$ for 10001 -hr cycles; (a, b) as-received; (c, d) $\mathrm{H}_{2}$-annealed. (Note slight immersion effect for as-received sample and reduced spallation for $\mathrm{H}_{2}$-annealed sample). 

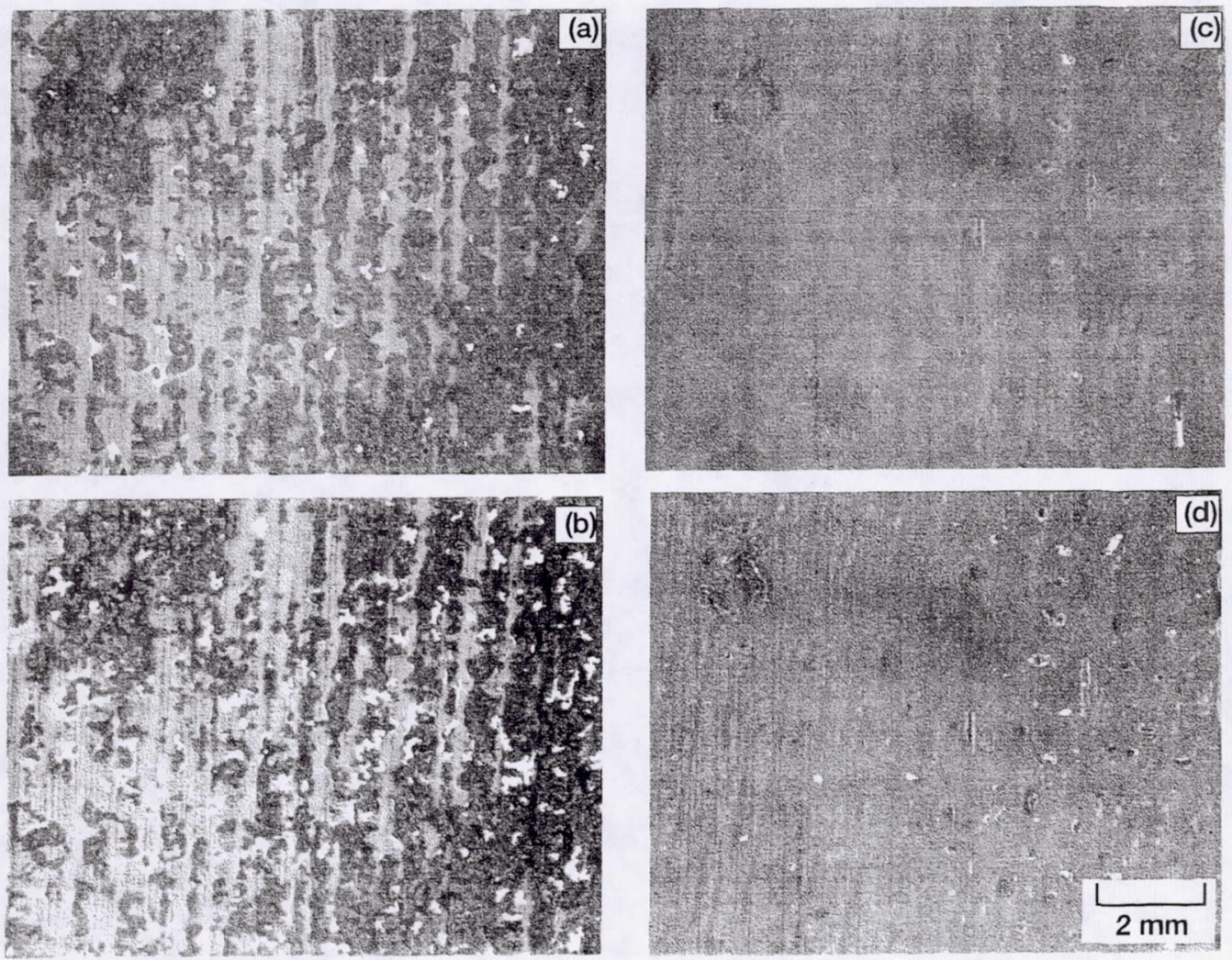

Figure 10.-Surface spallation appearance of alloy $103 \mathrm{Y}$ before and after water immersion; Rene'N5 oxidized at $1150^{\circ} \mathrm{C}$ for 10001 -hr cycles; (a, b) as-received; (c, d) $\mathrm{H}_{2}$-annealed. (Note moderate immersion effect for as-received sample and reduced spallation for $\mathrm{H}_{2}$-annealed sample). 

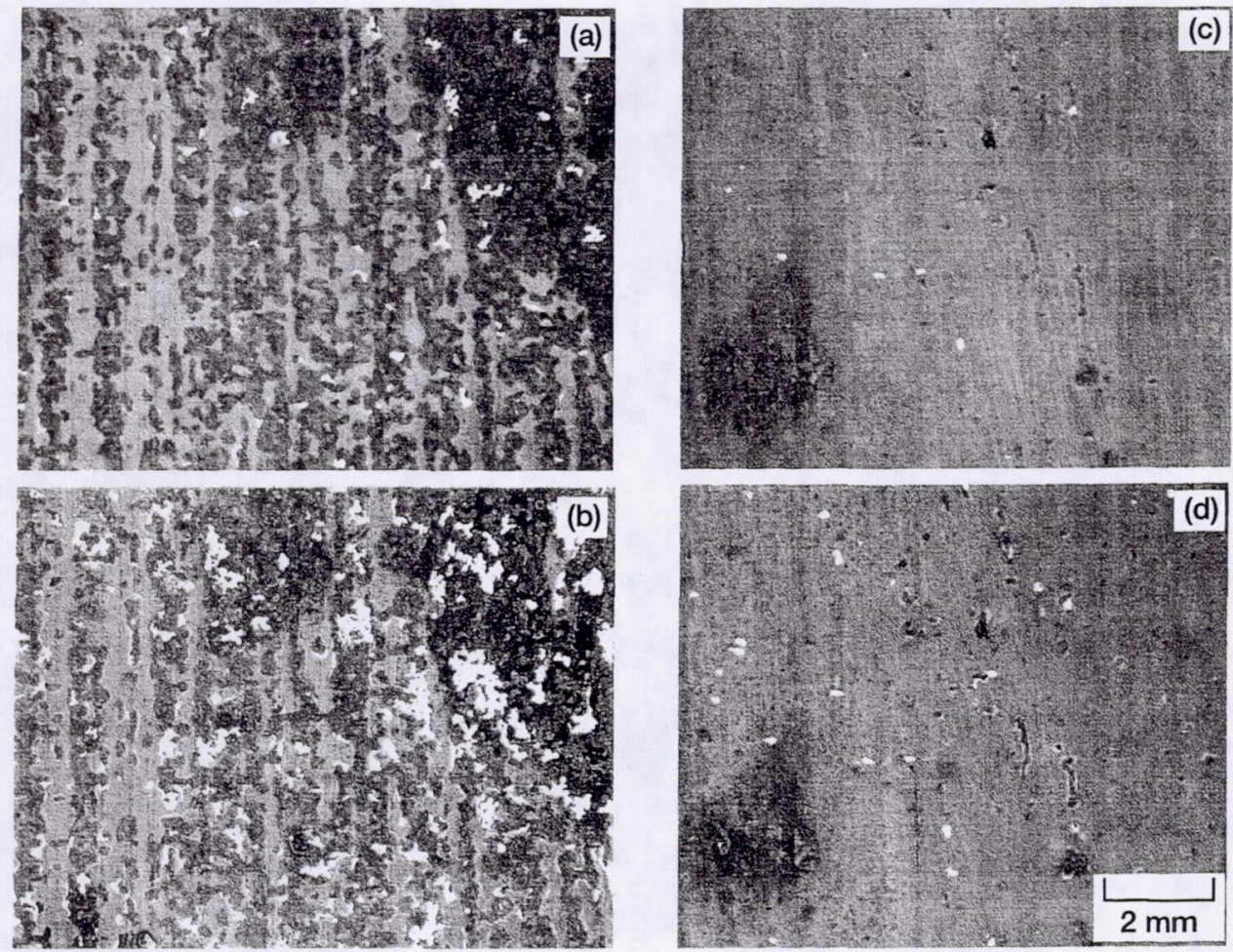

Figure 11.-Surface spallation appearance of alloy $105 \mathrm{Y}$ before and after water immersion; Rene'N5 oxidized at $1150^{\circ} \mathrm{C}$ for 1000 1-hr cycles; (a, b) as-received; (c, d) $\mathrm{H}_{2}$-annealed. (Note moderate immersion effect for as-received sample and reduced spallation for $\mathrm{H}_{2}$-annealed sample). 

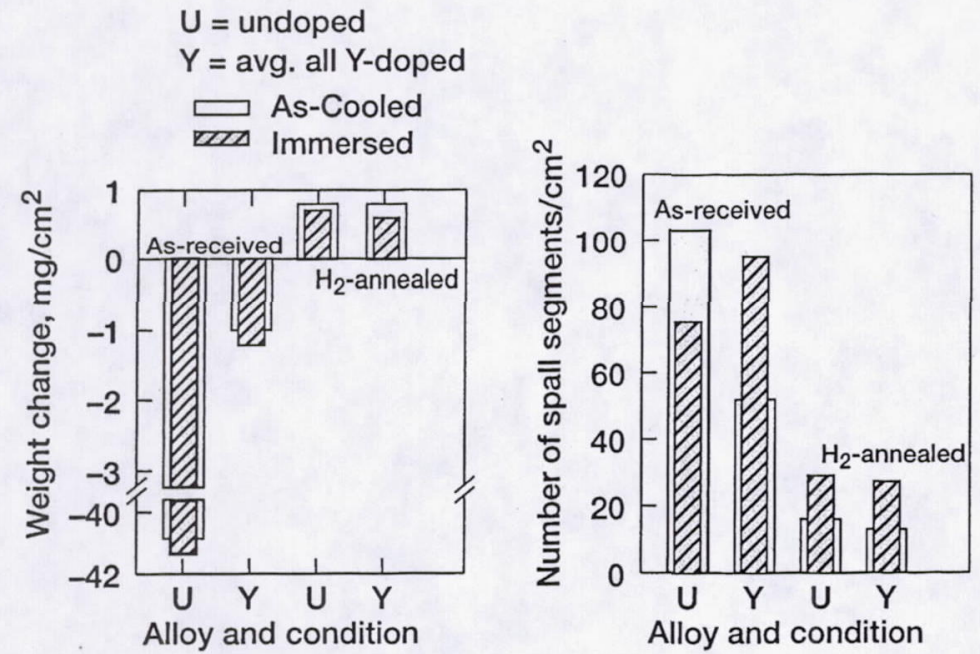

Figure 12.-Increase in scale spallation due to water immersion for Rene'N5 oxidized at $1150^{\circ} \mathrm{C}$ for 10001 -hr cycles, showing effects of $\mathrm{Y}$-doping (average data from Table $\mathrm{I}$ ) and hydrogen annealing. (a) Specific weight changes. (b) Number of spall segments, (c) Relative spall areas. 


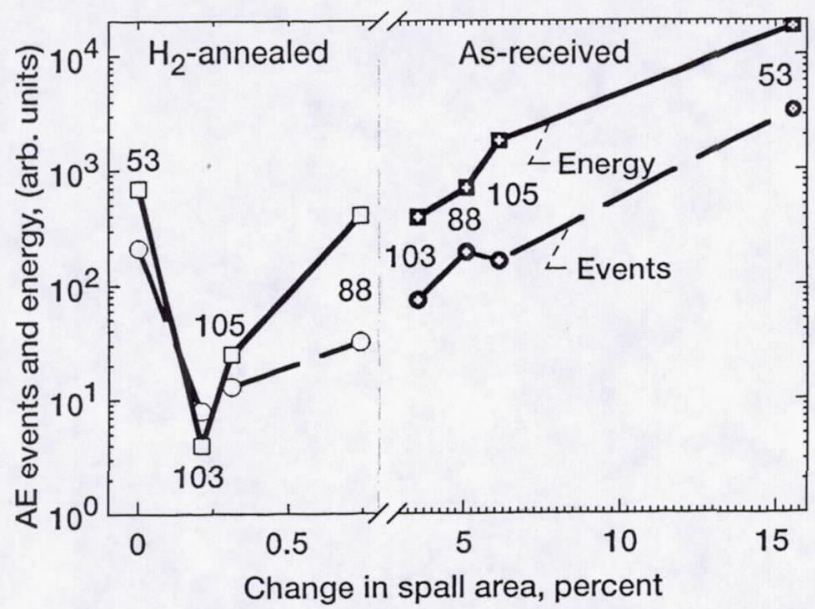

Figure 13.-Increasing trends in immersion-induced $\mathrm{AE}$ response with measured immersion-induced spall area for Y-doped Rene'N5 alloys, 53-105, after $1000 \mathrm{hr}$ oxidation at $11500^{\circ} \mathrm{C}$. 


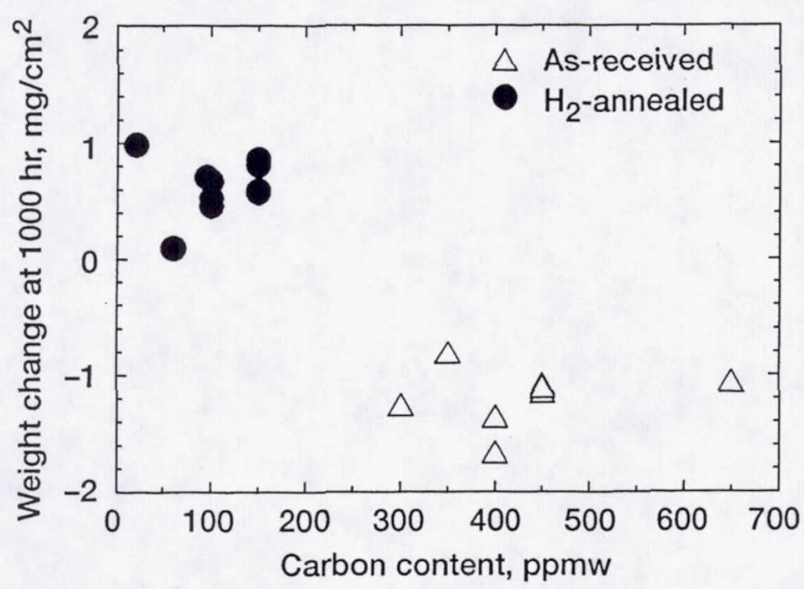

Figure 14.-Correlation scatter plot of final weight change with carbon content for as-received and hydrogen annealed Rene'N5, oxidized at $1150^{\circ} \mathrm{C}$ for 10001 -hr cycles. 


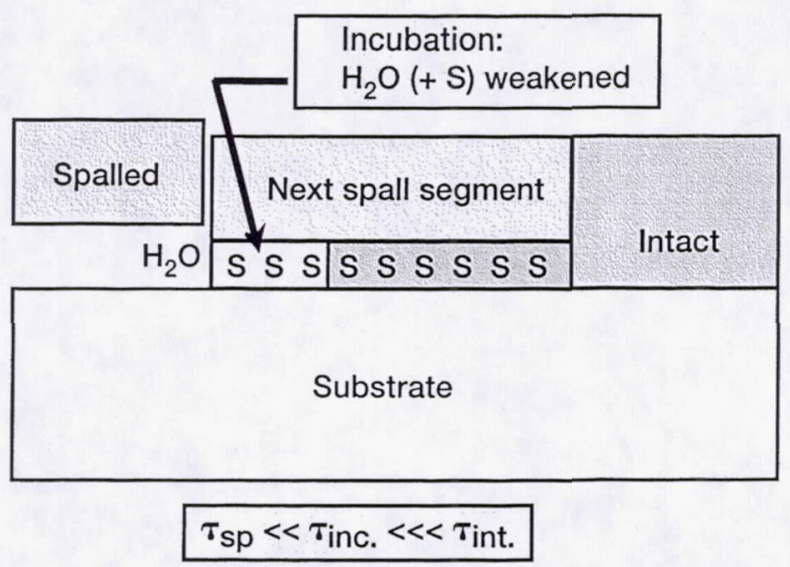

Figure 15.-Schematic sequence of moisture-induced spallation events. Rapid spallation $\left(\Delta \tau_{\mathrm{sp}}\right)$ preceded by a finite incubation time $\left(\Delta \tau_{\text {inc }}\right)$ of bond-weakening near exposed interfaces. 